\section{Memory development in children: Evidence from nonverbal tasks*}

\author{
KEITH E. NELSON \\ Stanford University, Stanford, Calif. 94305
}

Across the age range of 7-13 years, younger and older children showed equivalent immediate retention and equivalent long-term forgetting in picture recognition. But older children were better than younger children in reconstructing from memory an arrangement of six to nine picture cards. These results are interpreted in terms of different developmental patterns for different component processes in memory tasks.

The child's ability to recall, recognize, or reproduce previously presented information has been shown to improve with increasing age for a large and diverse set of tasks. Within this diversity lies a typical reliance on verbal response measures and on stimulus material consisting either of familiar verbal items or of nonverbal items which can be efficiently coded in terms of familiar verbal items. Differences in verbal skills of older and younger children are very likely to contribute heavily to age-related differences in such "verbal" tasks, a probability borne out clearly in studies by McCullers (1965), Keeney et al (1967), and Kingsley \& Hagen (1969).

Children in the present study provided evidence on age-related differences and similarities in mnemonic processes in two "nonverbal" tasks. The tasks were nonverbal in a triple sense-no verbal stimuli were presented as items to be remembered, the items presented were complex pictures judged by two adults as difficult to label in distinctive verbal terms within a brief presentation period, and no verbal responses were required of the children in order to indicate retention.

\section{METHOD}

Twenty Ss were drawn from each of Grades 1, 4, and 7 in suburban schools.

In a picture recognition task, Ss viewed colored slides of three general picture types: realistic paintings, abstract paintings, and puzzle pieces. Slides were taken of small color prints of the paintings or of individual pieces of an intricate jigsaw puzzle. Each realistic painting included elements readily interpreted by two adult judges as unambiguous representations of common physical referents (e.g., houses, boats, clothing), while each puzzle piece and each abstract painting included no representations so judged. The puzzle pieces were judged less

*Supported in part by NIH Grant 1EAA-40494420. Thanks are extended especially to Doris Welch, Eleanor Walker, and Jane Walker. complex and less variable in terms of contour and color patterns than either the realistic or abstract paintings; discriminability, and therefore recognition performance, was expected to be poorest for the puzzle pieces.

Each $S$ individually viewed a presentation series of 60 slides (20 of each picture type), 18 test pairs (6 pairs of each picture type) immediately following the presentation series, and another 18 test pairs ( 6 pairs of each picture type) 14 days later. In each test pair, one slide was "old" (included in the presentation series) and one slide was "new." Ss answered the query, "Which one did you see before?" by pointing or by saying "left" or "right" (or equivalents to these terms). Lateral position in test pairs was determined randomly within the restriction that left and right positions were occupied by old and new stimuli equally often in each session. No slide was used in more than one test pair. In each test series, equal numbers of each picture type occurred within the first and second halves, no more than three stimuli of the same type occurred consecutively, and equal numbers of "old" slides were drawn from the first and second halves of the presentation series. Beyond these restrictions, order was determined randomly. A single presentation and test order held for all Ss.

Presentation slides were projected singly with an interval between slides of $.26 \mathrm{sec}$ and an exposure duration, constant for each child, of either $\mathbf{8 0}$ or $5 \mathrm{sec}$. At each age level, five boys and five girls were assigned randomly to each exposure duration condition. Number of correct recognition choices entered analysis of variance as the dependent variable. It was anticipated that the variations in picture type and diverse levels of immediate performance within each age group, thereby permitting developmental conclusions on long-term forgetting rates that would be free of artifacts exposure duration would produce attributable to different initial performance levels for younger and older children.

A pattern reconstruction task was administered to each $\mathrm{S}$ immediately following the delayed test in picture recognition. The patterns were composed of small cards, each complex in color and contour patterning, placed within outline matrices formed of black tape on plywood. Using the criteria given above for picture types, some of the cards in each pattern were judged by two adults as realistic and others were judged as abstract. The three patterns, in order of presentation after an initial illustrative pattern, were: (1) three cards placed in one row; (2) six cards in two rows of three each; and (3) nine cards placed in three rows of three each. For each pattern, the appropriate empty matrix for reconstructing the pattern was first provided to the $S$, the pattern was presented for $10 \mathrm{sec}$ in slide form, and immediately after the slide presentation ended, the child was given the appropriate cards in a randomly ordered stack and asked to make a pattern just like the presented pattern. Numbers of correctly placed cards entered an analysis of variance with age ( $7,10,13$ years), sex, and pattern size $(3,6,9$ cards $)$ as independent variables.

\section{RESULTS}

The pictures were recognized equally well by children in the three age groups. Grade 1 Ss made correct choices for $24.5(\mathrm{SD}=3.30)$ of the 36 test pairs, and corresponding means for Grade 4 and Grade 7 Ss were 24.6 $(\mathrm{SD}=4.50)$ and $25.1(\mathrm{SD}=4.45)$. The only reliable effect including age as a factor was a weak ( $F=3.34$, $\mathrm{d} f=2 / 48, \quad \mathrm{p}<.05) \quad$ Age by Sex interaction representing means for boys which were slightly higher at Grade 1 and lower at Grade 7 than respective means for girls. In contrast, as Fig. 1 illustrates, recognition performance was strongly related to exposure duration, interval, and picture type. Mean correct choices of $27.1(\mathrm{SD}=2.99)$ and $22.4(\mathrm{SD}=3.61)$ were made by Ss viewing slides at exposure durations of 5.00 and $.80 \mathrm{sec}$, respectively $(\mathrm{F}=30.11$, $\mathrm{df}=1 / 48, \mathrm{p}<.001)$. As expected, immediate recognition performance (14.0 for 18 test choices, $\mathrm{SD}=2.14$ ) was substantially higher than recognition performance (10.8 for 18 test choices, $\mathrm{SD}=2.55$ ) by the same children after an interval of 14 days ( $F=137.37, \quad \mathrm{df}=1 / 48, \quad \mathrm{p}<.001$ ). Realistic paintings were recognized in 9.5 of 12 test pairs $(\mathrm{SD}=1.75)$, while abstract paintings and puzzle pieces were recognized, respectively, in 8.5 $(\mathrm{SD}=1.91)$ and $6.8(\mathrm{SD}=1.61)$ pairs 


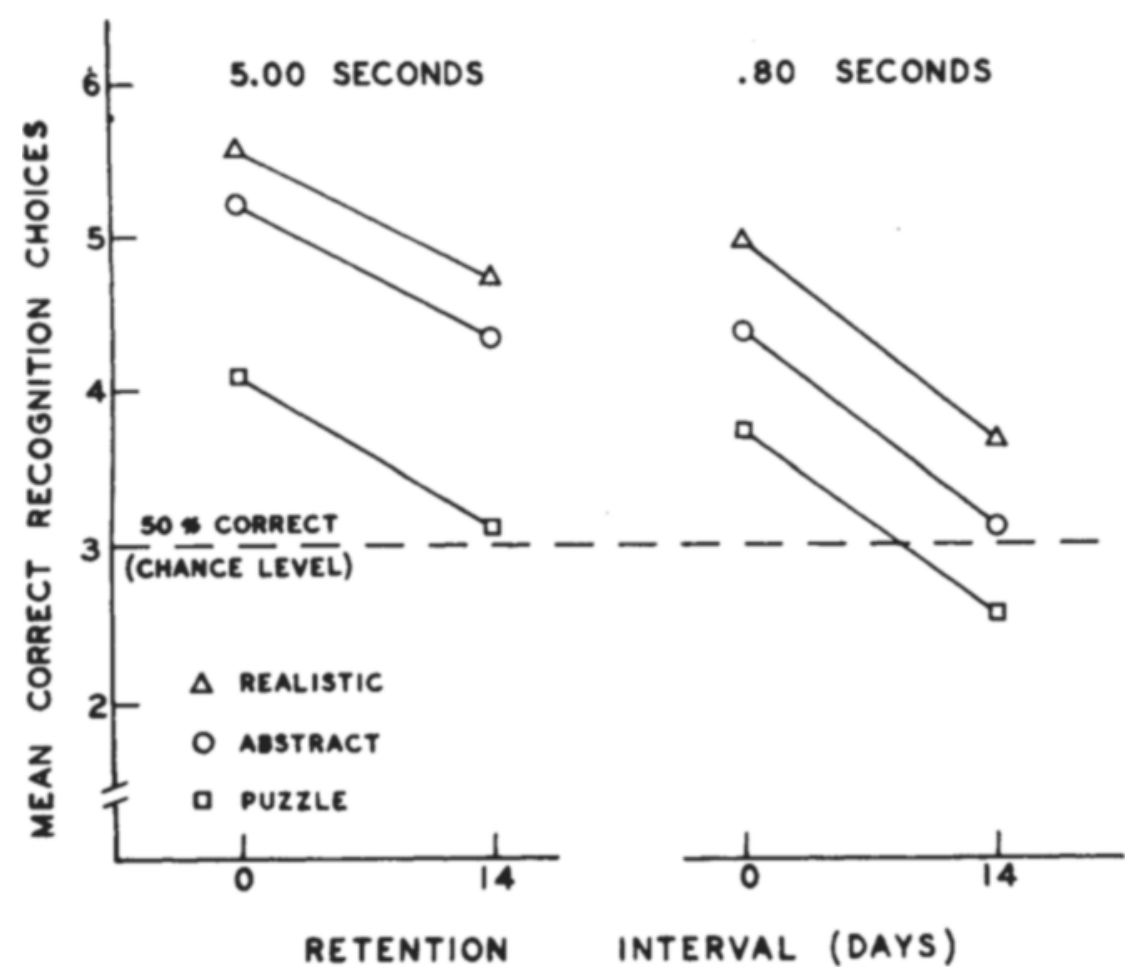

Fig. 1. Picture recognition as a function of picture type, exposure duration at initial presentation, and retention interval between initial presentation and recognition test. Each point on the graph represents the mean performance of 30 children, 10 children at each of Grades 1, 4, and 7. (Performance did not vary by grade level.)

(overall $F=61.48, \quad \mathrm{df}=2 / 96$, $\mathrm{p}<.001$; for each pair of means, $F \geqslant 32.57$, df $=1 / 96, p<.001$ ). The only other statistically significant effects were two unexplained interactions, both weak relative to the main effects-Exposure Duration by Picture Type ( $\mathrm{F}=3.18, \mathrm{df}=2 / 96$, $\mathrm{p}<.05)$ and Exposure Duration by Sex by Interval $(F=10.27, \mathrm{df}=1 / 48$, $\mathrm{p}<.01$ ).

Older children were significantly better in pattern reconstruction than younger children $(F=7.23, \mathrm{~d} f=2 / 54$, $\mathrm{p}<.01)$. Respective means, given 18 possible correct placements, for Grades 1, 4, and 7 were 9.60 $(\mathrm{SD}=3.79), \quad 12.50 \quad(\mathrm{SD}=3.40)$, and 13.75 ( $\mathrm{SD}=3.54)$, respectively. Performance was also strongly related to pattern size $(\mathrm{F}=25.50, \mathrm{df}=2 / 108$, $\mathrm{p}<.001$ ), as reflected by means of $2.82(\mathrm{SD}=0.62), 4.22(\mathrm{SD}=1.83)$, and $4.92(\mathrm{SD}=3.54)$, respectively, for patterns with three, six, and nine cards. However, Ss at each grade level performed comparably with the three-card pattern, showing means of 2.65 (Grade 1), 3.00 (Grade 4), and 2.80 (Grade 7); further means of 3.45 , 4.10 , and 5.10 with the six-card pattern and $3.50,5.40$, and 5.85 with the nine-card pattern-for Grades 1, 4, and 7 , respectively-reveal higher performance by older $S s$ and an interaction of age with pattern size relation to a conception of "memory" task performance as a complex of many component processes, including perception, storage, decay, retrieval, and report of information. Different patterns of development for two such components are suggested by the present findings.

One component, the rate of forgetting across varying retention intervals, does not seem to change with development. Broad developmental evidence to this effect was provided by 7- to 13-year-olds in the nonverbal recognition task of this study; equivalent performance across age for a variety of immediate performance levels was followed by equivalent forgetting by younger and older children across a retention interval of 2 weeks. And for realistic pictures presented for $5 \mathrm{sec}$, the condition most closely approximating (but not matching) similar research on adults (Shepard, 1967; Nickerson, 1968 ), the pattern of $93 \%$ immediate recognition and $79 \%$ recognition after 2 weeks by the children in this experiment is comparable to result patterns for adults. Long-term forgetting rates for similarly nonverbal tasks in children have not been reported previously. However, for verbal and nonverbal short-term memory studies which varied both retention interval and age, Belmont \& Butterfield (1969) similarly concluded that forgetting rates are equivalent across age.

In contrast to the data supporting age-equivalent rates of forgetting, present evidence indicates that skill in executing complex test or report responses increases with increasing age. In order to avoid confounding with age-related differences in verbal skills, this is a factor best examined in nonverbal tasks. In the slide recognition task and the three-card reconstruction task of this study and in two other nonverbal memory tasks in which age-equivalent levels of performance were also observed (Klugman, 1944; Belmont, 1967), the response required was relatively simple; in this study, the responses were indicating which of two pictures had been presented previously or reconstructing the placement of two cards (the third card in the three-card pattern could then be placed without reliance on memory). The six- and nine-card pattern reconstruction tasks of this study, as well as a variety of nonverbal recognition and reconstruction tasks also associated with better performance by older than younger children (Bruner \& Kenney, 1966 ; Munsinger, 1967 ; Paraskevopoulos, 1968; Corsini et al, 1968; Haith et al, 1970), instead required a series of responses or a single response choice from numerous 
alternatives. One hypothesis consistent with these results is that in nonverbal tasks requiring complex responses to indicate retention, younger $S$ s were as likely as older $S s$ to retrieve information presented but were less likely to use this information effectively to generate the task-required responses. But hypotheses that younger children were storing or retrieving less information than older children or adults cannot be dismissed. Single-response techniques of assessing memory, profitably used in recent developmental work by Sheingold (1971), appear particularly promising for the pursuit of discriminating evidence on these hypotheses.

Different developmental trends may also hold for different component processes in recognition and reconstruction. The critical developmental data are not yet available, but work on memory in adults suggests fundamental process differences between recognition memory and memory assessed in other response modes (cf. Kintsch, 1970). So it would not be surprising if differences between recognition and reconstruction response modes contributed somewhat to the contrasting developmental result patterns for the two tasks in this study. However, research findings discussed immediately above indicate that these contrasting test modes have not been associated in all cases with contrasting performance patterns in relation to age.

Even though we now have relatively little differentiated developmental information on component processes contributing to performance in memory tasks, one more general observation is in order. From currently available evidence, despite the generally higher levels of retention by older than by younger Ss, remarkable similarity across age in mnemonic processes can be inferred from the similar patterns of impact for numerous experimental variables (cf. Flavell, 1970; Calfee, 1970; Cole et al, 1971). In the present recognition experiment, these variables include exposure duration and picture type as well as retention interval.

\section{REFERENCES}

BELMONT, J. M. Perceptual short-term memory in children, retardates, and adults. Journal of Experimental Child Psychology, 1967, 5, 114-122.

BELMONT, J, M., \& BUTTER FIELD, E. C. The relations of short-term memory to development and intelligence. In L. P. Lipsitt and H. W. Reese (Eds.), Advances in child development and behavior. Vol. 4. New York: Academic Press, 1969. Pp. 29-82.

BRUNER, J. S., \& KENNEY, H, J. On multiple ordering. In J. S. Bruner, R. R. Olver, P. M. Greenfield et al (Eds.), Studies in cognitive growth. New York: Wiley, 1966. Pp. 154-167.

CALFEE, R. C. Short-term recognition memory in children. Child Development. $1970,4,145-161$.

COLE, M.. FRANKEL, F., \& SHARP, D. Development of free recall learning in children. Developmental Psychology. $1971,4,109-123$.

CORSINI, D. A., PICK, A. D., \& FLAVELL, J. H. Production deficiency of non-verbal mediators in young children. Child Development, 1968, 39 53-58.

FLAVELL, J. H. Developmental studies of mediated memory. In $\mathrm{H}$. W. Reese and L. P. Lipsitt (Eds.) Advances in child development and behavior. Vol. 5. New York: Academic Press, 1970. Pp. 182-211.

HAITH, M. M., MORRISON, P. J., SHEINGOLD, $K$ \& MINDES, $P$. Short-term memory for visual information in children and adults. Journal of Experimental Child Psychology, 1970, 9, 454-469.

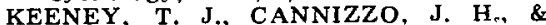
FLAVELL, J. H. Spontaneous and induced verbal rehearsal in a recall task. Child Development, 1967, 38, 953-966.

KINGSLEY, P, R., \& HAGEN, J. W. Induced versus spontaneous rehearsal in short-term memory in nursery school children. Developmental Psychology, $1969,1,40-46$.

KINTSCH, W. Models for free recall and recognition. In D. A. Norman (Ed.), Models of human memory. New York: Academic Press, 1970. Po. 331-373.

KLUGMAN, S. F. Memory for position among children, as measured by serial reproduction. British Journal of Psychology, 1944, 35, 17-24.

McCULLERS, J. C. Correlates of verbal paired-associate learning in children. Psychological Reports, 1965, 17, 747-752.

MUNSINGER, H, Developing perception and memory for stimulus redundancy. Journal of Experimental Child Psychology, 1967, 5, 39-49.

NICKERSON, R. S. A note on long-term recognition memory for pictorial material. Psychonomic Science, 1968, 11. 58.

PARASKEVOPOULOS, I. Symmetry, recall, and preference in relation to chronological age. Journal of Experimental Child Psychology, 1968,6, 254-264.

SHEINGOLD, K. Unpublished study reported in $M$. M. Haith, Developmental changes in visual information processing and short-term visual memory. Human Development, 1971, in press.

SHEPARD, $R$. N. Recognition memory for words, sentences and pictures. Journal of Verbal Learning \& Verbal Behavior, $1967,6,156-163$. 